\title{
A moderna química de produtos naturais no Brasil: as origens do Núcleo de Pesquisas de Produtos Naturais da UFRJ
}

\author{
The modern chemistry of natural products in Brazil: the origins \\ of the Núcleo de Pesquisas de Produtos Naturais da UFRJ
}

Depoimentos de

Affonso Prado Seabra Bioquímico

Walter Baptist Mors Químico

Apresentação de

Lina Faria

Historiadora, pesquisadora Fapesp de pós-doutorado no Departamento de Política Científica e Tecnológica da Unicamp

Ifaria@ige.unicamp.br
SEABRA, Affonso P.; MORS, Walter B.; FARIA, Lina.

A moderna química de produtos naturais no Brasil: as origens do Núcleo de Pesquisas de Produtos Naturais da UFRJ. História, Ciências, Saúde - Manguinhos,

Rio de Janeiro, v.14, n.1, p.347-362, jan.-mar. 2007.

Os depoimentos apresentam a história do Núcleo de Pesquisas de Produtos Naturais da Universidade Federal do Rio de Janeiro, criado em 1963 após a extinção do Instituto de Química Agrícola, do Ministério da Agricultura. Decorridos quase cinqüenta anos, dois dos remanescentes do antigo instituto contam as suas versões desta história.

PALAVRAS-CHAVE: história da ciência; instituições de pesquisa e pós-gradução; Núcleo de Pesquisa de Produtos Naturais da Universidade Federal do Rio de Janeiro; Paulo da Silva Lacaz; Affonso do Prado Seabra; Walter Baptist Mors; Benjamin Gilbert; Jaime Rabi.

SEABRA, Affonso P.; MORS, Walter B.; FARIA, Lina. The modern chemistry of natural products in Brazil: the origins of the Núcleo de Pesquisas de Produtos Naturais da UFRJ. História, Ciências, Saủde - Manguinhos, Rio de Janeiro, v.14, n.1, p.347-362, Jan.-Mar. 2007.

The testimonies disclose the history of the Núcleo de Pesquisas de Produtos Naturais da Universidade Federal do Rio de Janeiro, created in 1963, after the closure of the Instituto de Química Agrícola (Agricultural Chemistry Institute), Ministry of Agriculture. Almost 50 years.

KEYWORDS: history of science; research and graduate study organizations; Núcleo de Pesquisa de Produtos Naturais da Universidade Federal do Rio de Janeiro; Paulo da Silva Lacaz; Affonso do Prado Seabra; Walter Baptist Mors; Benjamin Gilbert; Jaime Rabi. 


\section{Apresentação}

\section{Lina Faria}

$\mathrm{O}$

s relatos do bioquímico Affonso do Prado Seabra ${ }^{1}$ e do químico Walter Baptist

Mors $^{2}$ sobre a formação do Centro de Pesquisa de Produtos Naturais (CPPN), no Rio de Janeiro, em 1963, nos remetem aos primeiros anos do Instituto de Química Agrícola (IQA). Esse instituto, fundado em 1918, foi uma referência no campo de química orgânica nacional. Os depoimentos ora publicados mostram o afloramento e os frutos de uma tradição científica nessa área, graças aos impulsos inovadores que receberam de cientistas como Otto Richard Gottlieb, ${ }^{3}$ Benjamin Gilbert, ${ }^{4}$ Oscar Ribeiro ${ }^{5}$ e Paulo da Silva Lacaz. ${ }^{6}$

Nos laboratórios do IQA, que funcionavam ao lado do Jardim Botânico, conviviam ativamente químicos, farmacêuticos, botânicos e agrônomos. A história do instituto está associada às trajetórias desses cientistas - "representantes da nata da química brasileira", conforme as palavras de Seabra - , cujas pesquisas contribuíram para a formação de profissionais nas áreas de química orgânica e de química de produtos naturais no Brasil. Na década de 1950 o instituto projetou-se como'ilha de competência' no cenário nacional e internacional. ${ }^{7}$ Entretanto foi afetado pelas mudanças ocorridas no Ministério da Agricultura e no setor agrícola nacional. As idéias de modernidade e desenvolvimento tecnológico e uma visão mais pragmática e imediatista de produção de ciência acabaram por fragilizar a instituição. A extinção desse centro de excelência em $1962^{8}$ não significou, no entanto, o fim das importantes tradições científicas que ali brotaram. Ao contrário; como um efeito paradoxal, deu-se a disseminação do conhecimento de seus profissionais, uma vez que estes organizaram novos centros de pesquisa de produtos naturais em vários estados brasileiros.

Walter Mors e Benjamin Gilbert foram convidados por Paulo da Silva Lacaz para organizar o Centro de Pesquisas de Produtos Naturais (CPPN), atual Núcleo de Pesquisas de Produtos Naturais (NPPN), na Faculdade de Farmácia da Universidade Federal do Rio de Janeiro (UFRJ). Otto Gottlieb, por sua vez, organizou o Departamento de Química Orgânica do Instituto Central de Química da Universidade de Brasília. Os renomados cientistas dariam, assim, continuidade aos trabalhos pioneiros que realizaram no IQA, onde teve início a moderna fitoquímica brasileira.

No depoimento ora publicado, Prado Seabra lembra grandes nomes e acontecimentos que marcaram a trajetória da química orgânica no Brasil. Veja-se, por exemplo, o que diz sobre os concorridos concursos para professor catedrático, quando ainda era estudante na Faculdade de Farmácia, ou sobre o convite que recebeu para compor a equipe de Paulo Lacaz, na Faculdade de Farmácia. As eventuais referências anedóticas (como a alusão à performance gestual de Paulo de Góes, na disputa pela cátedra) não devem desviar a atenção do leitor para um fato maior: os grandes embates acadêmicos que se revelavam nos concursos públicos de então e que marcaram época. O mesmo se aplica aos 'convites' dos maiorais para que um jovem ingressasse numa equipe de pesquisa. É de notar que, mesmo sem passar pela exigência de concursos - que nem sempre premiam o nome mais indicado para determinada linha de pesquisa - o que contava, em tais convites, eram competências e desempenhos na atividade científica e não ajustes ou acordos pessoais.

Seabra relembra ainda um tempo que antecedeu o apoio oficial maciço à ciência no Brasil, marcado, então, pela atuação de algumas grandes fundações norte-americanas 
na filantropia científica. Segundo ele, muitos profissionais da área de química orgânica do país, do próprio IQA e de outras áreas científicas tiveram oportunidade de estagiar no exterior graças a bolsas de estudos financiadas por instituições estrangeiras. Os contatos estreitos dos pesquisadores do instituto com universidades e fundações estrangeiras se traduziram, também, na vinda de pesquisadores da categoria de Carl Djerassi, doutor em química pela Universidade de Wisconsin e pesquisador da Wayne State University, em Detroit.

Em 1956 foi a vez de Walter Mors receber uma bolsa de estudos da Fundação Rockefeller. Mors foi convidado por Carl Djerassi para estagiar em seu laboratório e adestrar-se nas técnicas analíticas e de isolamento e purificação de produtos naturais. Como salienta no presente depoimento, "fui eu que escolhi Djerassi como orientador, em virtude de seus trabalhos sobre produtos naturais, realizados no México". Esse contato com Djerassi hoje sabemos - marcou o início da era moderna da química agrícola no Brasil. Após o regresso de Mors, o núcleo que se dedicava ao estudo dos produtos naturais no IQA cresceu e se desenvolveu. Além de importar o primeiro espectrofotômetro de infravermelho, ele incentivou a vinda de vários cientistas estrangeiros para realizar pesquisas no instituto. Um desses foi Benjamin Gilbert, ex-aluno de Djerassi. Nas palavras de Prado Seabra, "assim formou-se, possivelmente, um dos melhores grupos científicos no Brasil".

Os motivos que levaram à extinção do IQA foram resgatados por Prado Seabra, em sua narrativa. Ele relembra os tumultuados anos de 1960. Seu comentário irônico sobre o 'brilho' de um assessor do ministro da Agricultura revela a miopia e as limitações produzidas pela ideologia nacionalista daquele tempo, no que diz respeito à produção científica. Segundo Seabra a veiculação da notícia, absurda, de que o IQA estaria sendo

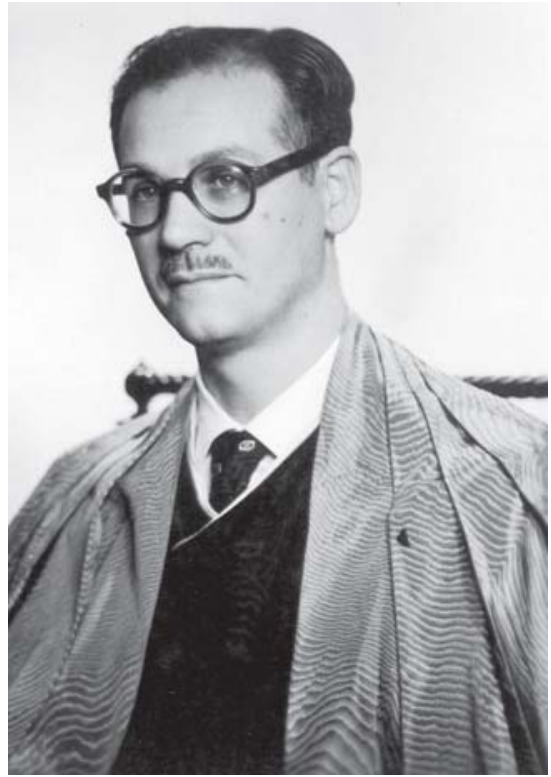

Paulo da Silva Lacaz, professor de química orgânica e de bioquímica das Faculdades de Medicina e de Farmácia da Universidade do Brasil. Grande incentivador do Núcleo de Pesquisa de Produtos Naturais. (Arquivo pessoal de Walter Mors) financiado por Wall Street foi um tiro mortal na instituição.

Sobre o outro equívoco dos assessores do então ministro - o suposto desvio de funções da instituição, ao produzir pesquisa pura e não aplicada Walter Mors lembra, em depoimento concedido aos pesquisadores da Casa de Oswaldo Cruz, em 1997, que o Ministério da Agricultura não tinha interesse pelo tipo de pesquisa implementada na instituição. ${ }^{9}$ De fato, para os cientistas do IQA, cuja vocação era essencialmente científica, desenvolver tecnologia não era tão importante quanto a pesquisa fundamental.

Em 11 de outubro de 1962, através da lei delegada $n^{\circ} 8$, o presidente João Goulart criou, no Ministério da Agricultura, o Fundo Federal Agropecuário, com o objetivo de estimular e ampliar a ação dos serviços "encarregados dos trabalhos de pesquisa, experimentação, assistência técnica, promoção e organização rural, visando o aumento da produção e da produtividade agropecuária". No mesmo dia, a lei delegada ${ }^{\circ} 9$ reorganizava o Ministério da Agricultura e extinguia o tão polêmico IQA. Foi assim, na opinião de Prado Seabra, que, "num piscar de 
olhos, sumiu o Instituto de Química Agrícola". Entretanto, apesar desse ato ministerial despropositado (não haveria lugar para a pesquisa fundamental no Ministério?), ainda no período Goulart observam-se as primeiras iniciativas de fomento a órgãos de pesquisa aplicada como a Empresa Brasileira de Pesquisa Agropecuária (Embrapa).

De todo modo, como foi dito anteriormente, a desestruturação do IQA não significou o fim de uma tradição científica, já que seus cientistas prosseguiram seus trabalhos em diferentes regiões do país. Além disso, no âmbito desse grupo germinou a semente do que viria a ser, anos mais tarde, o Centro (atual Núcleo) de Pesquisas de Produtos Naturais (CPPN), fundado na Faculdade de Farmácia da então Universidade do Brasil em setembro de 1963, um ano após a desarticulação do instituto. ${ }^{10}$

O quadro do novo centro foi, a princípio, formado por Paulo da Silva Lacaz, Walter Mors, Benjamin Gilbert, Joaquim Martins Ferreira Filho e Keith S. Brown Jr. Inicialmente - lembra Prado Seabra - contaram com o apoio da Universidade de Stanford, em larga medida graças a Carl Djerassi, que para lá havia se transferido. Com o tempo, o contato com outras instituições estrangeiras, o apoio de instituições brasileiras como o Conselho Nacional de Desenvolvimento Científico e Tecnológico (CNPq) e a Financiadora de Estudos e Projetos (Finep) e novas linhas de amparo à pesquisa possibilitaram, ao CPPN, a aquisição de equipamentos modernos e o aperfeiçoamento da química de produtos naturais. ${ }^{11}$

Affonso do Prado Seabra, assim que retornou de seu estágio na Inglaterra, passou a fazer parte do grupo, assim como Hugo J. Monteiro e Paul M. Baker. Prado Seabra e Walter Mors recordam o importante papel deste último na montagem da Central Analítica, "um marco na evolução da ciência química no Brasil".

Passagem interessante das recordações de Prado Seabra diz respeito à mudança de nome da instituição - de Centro de Pesquisas de Produtos Naturais para Núcleo de Pesquisas de Produtos Naturais (NPPN). Para evitar que o CPPN fosse "um centro dentro de outro centro" na universidade - o de Ciências da Saúde - e que fosse objeto de críticas formais por parte do Conselho Universitário, o então reitor Alcides Caldas propôs a mudança de designação. O que se depreende, nos depoimentos transcritos, é que a "lealdade coletiva" - para lembrar o termo consagrado por Robert K. Merton - era o verdadeiro ponto de honra para os membros do futuro núcleo, mais importante do que a luta por denominações, sempre fugazes. Walter Mors também lembra o dia em que o Conselho Universitário aprovou a troca de nomes, legitimando a existência, na universidade, do grupo formado por antigos cientistas do IQA. Antigos e novos membros, segundo ele, compartilhavam o interesse especializado nas pesquisas de produtos naturais, o que aproximava o novo NPPN da ciência biológica.

Walter Mors encerra sua narrativa homenageando Paulo da Silva Lacaz. Segundo Mors, "Lacaz foi um grande chefe", opinião que compartilha com Affonso Prado Seabra. O importante papel de cientistas do porte de Paulo da Silva Lacaz, Affonso do Prado Seabra, Walter Baptist Mors, Otto Richard Gottlieb, Benjamin Gilbert e muitos outros que contribuíram para a consolidação, no Brasil, das áreas de química de produtos naturais e de química orgânica no Brasil pertence agora à história institucional e à memória de gerações de químicos, bioquímicos, farmacêuticos e botânicos brasileiros e estrangeiros. O trabalho desses cientistas deixou sua marca em todo o campo científico internacional. 


\section{Núcleo de Pesquisas de Produtos Naturais: o destino de uma equipe}

\section{Depoimento de Affonso do Prado Seabra}

Foi fácil atender ao convite da Sônia Soares $\operatorname{Costa}^{12}$ para escrever as minhas lembranças sobre as origens do Núcleo de Pesquisas de Produtos Naturais, o NPPN. Antes de começar, porém, vale a pena pensar em quem lerá essas lembranças. Ora, alguns 'sobreviventes' vão querer conferir a exatidão de meu relato, mas tenho de admitir que algum estudante ou mesmo jovem professor (como a própria Sônia) talvez se interesse por essa narrativa.

In illo tempore não existiam os departamentos e tampouco o mestrado e o doutorado, tais como os conhecemos atualmente. A universidade era formada por cátedras, e um conjunto delas formava uma faculdade. Na verdade, nem mesmo existia a universidade, que foi criada para reunir entidades isoladas que já existiam muito antes dela. É o caso da Faculdade Nacional de Medicina ou da Faculdade de Direito. No nosso caso, foi criada a Universidade do Brasil, hoje chamada de Universidade Federal do Rio de Janeiro.

A verdadeira unidade universitária, a cátedra, era algo parecido com um império. Cada cátedra tinha apenas um professor catedrático, com poderes absolutos. Quando ele morria acontecia, então, um grande concurso para o preenchimento daquela vaga. Um concurso para catedrático era um grande acontecimento social e cultural, uma verdadeira guerra. No meu tempo de estudante, e pouco depois, acompanhei bem de perto algumas dessas batalhas: Carlos Chagas, Paulo de Góes e Paulo da Silva Lacaz. Se não me falha a memória, a do Góes foi a mais disputada. Seu oponente tinha imenso prestígio e era considerado favorito; o que ele não contava era com a capacidade que tinha Góes de escrever no quadro-negro com as duas mãos ao mesmo tempo. Um desbunde!

Quando, alguns anos mais tarde, retornei dos Estados Unidos com o mestrado feito com Herald Deutsch, em Wisconsin, recebi convite de três grandes mestres. O velho Paulo Seabra me aconselhou: "O Chagas já está com o Instituto de Biofísica a todo vapor, já reúne a nata dos cientistas do Rio de Janeiro. O Góes acabou de criar o seu Instituto de Microbiologia e não descansa enquanto não se igualar ao Chagas, o que não vai ser nada fácil. Por sua vez, o Lacaz está praticamente na estaca zero. Se você entrar para a equipe dele, facilmente ocupará uma posição que nem Chagas ou o Góes poderão oferecer!"

O caso de Lacaz era muito especial, na Faculdade de Medicina. No nome, sua cadeira de química orgânica e biológica era uma só, mas na verdade podíamos considerá-la como duas cátedras, a de química orgânica e a de química biológica. (Naturalmente a alma de Lacaz estava por completo nesta última.) Essa duplicidade agra- 
vou-se quando Lacaz conquistou a mesma cátedra na Faculdade de Farmácia. Na realidade não recordo qual das duas cátedras ele assumiu primeiro, mas a dúvida é irrelevante: o importante é que Lacaz deixou de ser um bicatedrático e passou a tetracatedrático.

Lacaz foi logo me dizendo: "Esquece a bioquímica! Tenho uma equipe muito bem formada, com Macedo, João Paulo de Campos, Maria Lúcia Salac, Sílvio Gonçalves e Hildete Farla. Eles dão aula dia e noite. O Macedo é uma máquina! Na farmácia estou também muito bem apoiado por Alice Terra e Zalmin! Você não precisa dar aula nenhuma, só quero que você organize os laboratórios de pesquisa".

Essa combinação valeu por muito pouco tempo. Alice Terra, uma pessoa maravilhosa, não tinha saúde para agüentar aquele rojão. Não teria sido maior problema se Zalmin assumisse a tarefa, mas inventaram um país novo, Israel, e ele achou que tinha obrigação de ir para lá, ajudar a erguê-lo. E assim eu, que nunca tinha cogitado ser professor, comecei a dar aula como um escravo!

Nessa época, em uma das inúmeras reformas universitárias, foi criado o Instituto de Química da UFRJ e fui eu transferido para lá.

A Faculdade de Farmácia era dirigida por Mário Taveira. Nunca descobri como ele conseguiu tanto dinheiro, mas o fato é que construiu um prédio muito espaçoso e agradável na Praia Vermelha. Lacaz deu-me uma enorme área, metade de um andar nesse prédio. $\mathrm{Na}$ ocasião, nem sequer sonhava com o destino importante que aquele espaço iria adquirir.

Aconteceu então um telefonema do Conselho Britânico. Vinha ao Brasil o presidente da Royal Society of Chemistry, um homem muito, muito importante. Stacey era não apenas o presidente da Royal Society of Chemistry, o que na Inglaterra não é pouca coisa, mas também o chefe da química na University of Birmingham. Ora, o Conselho Britânico decidiu comemorar o acontecimento com um grande banquete oferecido àquela universidade.

Não recordo se foi Paulo Lacaz ou Raymundo Moniz de Aragão que me encarregou de comparecer ao grande evento. Na hora $\mathrm{H}, \mathrm{o}$ reitor mandou avisar que não poderia comparecer. $\mathrm{O}$ vice-reitor, idem. O diretor do Instituto de Química, idem. Agora imaginem a cena feliniana: uma mesa enorme e uma longa fila de garçons, todos com aquela toalhinha pendurada no braço; na mesa, coberta de flores, o presidente da Royal Society of Chemistry, o diretor do British Council e eu - mais ninguém.

Durante o fausto ágape (é assim mesmo que se diz?) Stacey, o grande Maurice Stacey, me fez um milhão de perguntas transcendentais. Não falhei nenhuma vez, respondi a todas. Qual a cerveja predileta do Pelé? Eu, claro, chutei. O nome da mãe do Garrincha? Mais um chute. Se a minha mãe ouvisse aquela conversa nunca mais falaria comigo. O fato é que Stacey adorou o nosso papo e admirou a 
minha profunda competência futebolística. Ao nos despedirmos, ele disse para o diretor do British Council: "Dá uma bolsa para esse cara!" Assim fui parar em Birmingham, e esse 'passeio' me valeu a tese de doutorado e livre-docência.

Enquanto eu gozava as delícias de Birmingham, coisas terríveis aconteciam no Brasil, que atravessava um período politicamente muito conturbado. Em 1960 Jânio Quadros havia sido eleito presidente e João Goulart era seu vice-presidente. Como todos sabem, Jânio renunciou em agosto de 1961. Jango, mal-visto pelas Forças Armadas por causa de suas tendências esquerdizantes, inicialmente foi impedido pelos militares de assumir a Presidência. Criada a crise, foi a duras penas encontrada uma fórmula legal, embora forçada: a posse de Jango seria permitida se o Congresso aprovasse uma nova forma de governo, o parlamentarismo. Com esse jogo, o vice tomaria posse mas não governaria; o governo caberia de fato aos partidos, através do Gabinete. Jango aceitou e assumiu o cargo de presidente em setembro de 1961. O tempo de vigência do parlamentarismo foi outro motivo de discórdia entre os políticos. Marcado inicialmente para 1965, o fim do regime foi depois antecipado para 1963.

Existia, então, encravado no Jardim Botânico do Rio de Janeiro, uma das mais conceituadas instituições científicas do país, o Instituto de Química Agrícola (IQA) do Ministério da Agricultura. Aí trabalhavam alguns representantes da nata da química brasileira, notadamente Oscar Ribeiro, Otto Gottlieb e Walter Mors. Quando Walter decidiu estudar com o grande Carl Djerassi, na ocasião ainda da Wayne State University, em Detroit, este percebeu que podia fazer maravilhas associando-se a esse grupo brasileiro. Tal convicção intensificou-se depois que Walter voltou para o Brasil, em 1957. Naturalmente, ninguém tinha que explicar a Djerassi que os brasileiros não tinham dinheiro nem para comprar o papel de um espectrômetro infravermelho, muito menos, é claro, para o próprio aparelho. Djerassi, já então na Universidade de Stanford, começou a obter verba junto a grandes fundações americanas para mandar ao IQA. Em pouco tempo ele descobriu que além de dinheiro devia mandar gente, e assim formou-se, possivelmente, um dos melhores grupos de cientistas do Brasil.

Voltemos à política. Na falta de poderes para governar, foi concedida a Jango autorização para emitir um certo número de leis delegadas, que permitiriam ao presidente legislar em determinados assuntos. Uma delas, a lei delegada ${ }^{\circ}$ 8, de 11 de outubro de 1962, tratou da reforma estrutural do Ministério da Agricultura.

Dentro deste quadro, algum assessor brilhante convenceu o ministro da Agricultura, Renato Costa Lima, de duas grandes 'verdades'. A primeira referia-se ao desvio de funções de um instituto que, em vez de estudar batata e agrião, estava publicando trabalhos de 
ciência pura em revistas estrangeiras - "um escândalo!". A segunda era ainda pior: tudo isso era financiado com o "torpe dinheiro de Wall Street". João Goulart agiu imediatamente: mandou publicar no Diário Oficial a extinção daquele órgão tão vergonhoso e, também, a de dois outros institutos tecnológicos do Ministério da Agricultura que não estudavam batata nem agrião. Assim, num piscar de olhos, sumiu o IQA.

Lacaz, assim que soube do ocorrido pelos jornais, pegou o carro e foi ao Jardim Botânico. Reuniu-se com a equipe do instituto e disse: "Acabei de dar a um assistente um belíssimo e novíssimo laboratório. Ele foi passar uns tempos na Inglaterra, e o espaço está praticamente sem uso. É só vocês pegarem a chave e mudarem para lá".

Por certo Lacaz não tinha como pagar todo aquele pessoal, mas na época o CNPq começava a dar bolsas para pesquisador, sem falar no apoio de Djerassi. Quanto ao material científico, todo ele tinha sido comprado com dinheiro de grants americanos, e não havia por que não levá-lo para a Praia Vermelha.

Junto com os brasileiros Walter Mors e Joaquim Martins Ferreira vieram para a UFRJ os estrangeiros que trabalhavam no grupo. Não posso afirmar se Bernard Tursch, Keith Brown, Roderick Barnes, Paul Baker e Jaime Rabi já pertenciam à equipe ou se ingressaram mais tarde. Duas pessoas, no entanto, não podem ser esquecidas. Uma delas é Benjamin (Ben) Gilbert, figura ímpar que, além de destacado cientista, era um professor nato e, acima de tudo, um verdadeiro líder. A outra é Maria Luiza Conde Miranda (Marilu),

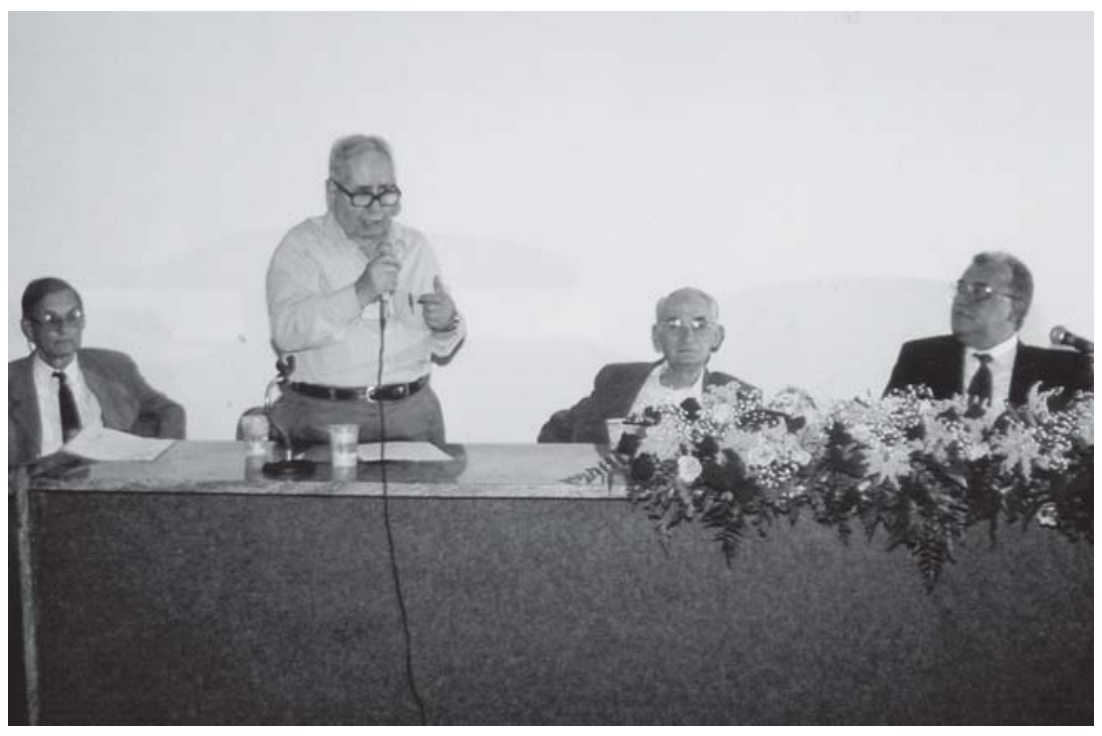

Os colegas Ben Gilbert, Nuno Álvares Pereira, Walter Mors e Antônio Jorge durante encontro científico promovido pelo Núcleo de Pesquisas de Produtos Naturais. (Arquivo pessoal de Walter Mors) 
secretária executiva que foi capaz de assumir uma operação de tão grande monta.

Quando Walter e Gilbert descarregaram aquela montanha de equipamento científico na Faculdade de Farmácia, Marilu determinou categoricamente: "Ninguém mete um prego nas paredes! Esse espaço é de um tal de Seabra, que ninguém conhece; ele bem pode ser um maluco agressivo e jogar tudo pela janela. Vamos esperar que ele volte da Inglaterra".

Nascia então o Centro de Pesquisas de Produtos Naturais. Como eu não estava aqui, não sei se foi Lacaz ou Walter Mors que o batizou com esse nome. Durante muito tempo, o CPPN funcionou de uma forma que é difícil, para os jovens de hoje, entender e acreditar. Qualquer assunto, por mais grave que fosse, era resolvido num papo entre Walter e Gilbert. Ninguém sabia ao certo qual dos dois era o chefe. No caso de ser necessário assinar algum documento importante, um boy o levava para o professor Lacaz. Afinal, perante a universidade, o CNPq e outros órgãos era ele o chefe. E Lacaz estava sempre disposto a assinar o que quer que fosse, ou mesmo comparecer a órgãos que solicitassem a sua presença.

Com a construção do Centro de Ciências da Saúde na ilha do Fundão, Lacaz recebeu três andares do Bloco $\mathrm{H}$, um prédio enorme e maravilhoso. Ele reservou o terceiro andar para a sua querida bioquímica e cedeu o primeiro andar e o subsolo para o CPPN.

Nessa época um dos pesquisadores do CPPN, o britânico Paul Baker, apareceu com a idéia de montar uma central analítica. Até então, análises mais sofisticadas como espectrometria de massas e ressonância nuclear magnética eram feitas em Stanford, nos laboratórios de Djerassi. Quando perguntei a Baker quanto custaria aquela 'brincadeira', levei um bom tempo para acreditar que ele falava sério: nunca ninguém tinha visto tanto dinheiro nas mãos de humildes professores universitários!

Acho que pedi a Paul Baker para escrever um projeto detalhado apenas para não parecer pura má vontade com seus sonhos amalucados. Na verdade, não estava levando em conta a dedicação de pessoas que, além de amigas, acreditavam completamente na seriedade do CPPN. Seria difícil listar todos, mas nomes como o do reitor Raymundo Moniz de Aragão e Antonio Conceiro, presidente do CNPq, Manoel da Frota Moreira e José Pelúcio Ferreira, da Finep, tornaram realidade os sonhos de Paul Baker. A Central Analítica do CPPN foi um marco na evolução da ciência química no Brasil.

Certo dia eu estava numa reunião do Conselho de Pesquisas e Ensino para Graduados da Universidade, quando o reitor Alcides Caldas apareceu e deitou falação. Não lembro o assunto, mas ele fez referências explícitas e altamente elogiosas ao CPPN. Depois da reunião, eu disse ao Caldas: 
- Gostei muito dos seus elogios ao CPPN. Você falou como se ele realmente existisse. Na verdade, ele 'parece que existe', porque produz cientificamente, publica nas principais revistas internacionais, tem um mestrado reconhecido pelo Ministério da Educação e pelo CNPq e recebe muito apoio financeiro da Finep. Mas tudo isso ocorre somente porque o professor Paulo Lacaz'permite que aconteça', porque ele cedeu dois terços do espaço do Departamento de Bioquímica para o CPPN se instalar no Fundão. Caso algo suceda com o Lacaz, o CPPN desaparecerá completamente em menos de 24 horas, e para os mais antigos, aqueles que viram o IQA ser fechado e extinto, seria simplesmente a reprise de um filme doloroso.

Caldas ouviu com paciência, olhou para mim e respondeu:

- Seabra, vamos fazer um horse trading. Você resolve um problema que tenho, e eu resolvo o seu problema! Assim, ficam elas por elas.

- Qual é o problema que eu poderia resolver?

- Depois da reforma universitária a UFRJ passou a ser formada por centros. Com isso, o Centro de Pesquisa de Produtos Naturais ficou vinculado ao Centro de Ciências da Saúde. Ora, é muita bagunça ter um centro dentro de outro, e já fui muito criticado por isso no Conselho Universitário. Se você trocar o nome de seu centro, eu acabo com os seus problemas.

- Negócio fechado!

Caldas chamou um assessor, ou algo parecido, e disse:

- Prepare toda a papelada para a criação de um órgão suplementar com o nome de Núcleo de Pesquisas de Produtos Naturais da UFRJ. Isso tem que ser aprovado no Conselho Universitário e publicado no Diário Oficial antes de terminar o meu mandato como reitor.

O horse trading estava consumado.

Pouco depois, cheguei no CPPN e dei as duas notícias: a criação definitiva, oficial do instituto criado por Lacaz, Walter e Gilbert e também (horse trading é horse trading) a mudança de nome. Passamos a nos chamar Núcleo de Pesquisas de Produtos Naturais.

Cada um tem o direito de ter suas próprias opiniões, e até hoje há quem considere um crime essa mudança de nome. Certamente qualquer jovem, hoje, dirá que o assunto deveria ser debatido em uma assembléia geral - desculpem, em várias. Pode ser que tenham razão. Mas se a questão não fosse resolvida antes que Caldas deixasse o cargo de reitor da UFRJ, não sei se existíriamos hoje. Afinal, não custa também lembrar que a própria Universidade Federal do Rio de Janeiro chamava-se, no meu tempo de estudante, Universidade do Brasil. Mudou de nome e continuou a existir.

No início deste texto, admiti a possibilidade de ele ser lido por jovens. Que a turma dos velhos sobreviventes vá ler é certo, ao menos para conferir se contei a história corretamente, ou se a 
memória já me trai. Mas tenho que enfrentar a perigosa pergunta que um jovem possa me fazer: "Depois de tantos anos, de tanto trabalho, o que você acha que o CPPN, ou melhor, NPPN tem a ensinar?".

Ora, seria fácil apresentar a listagem de publicações nas principais revistas internacionais; ou enumerar as teses de mestrado e doutorado; ou ainda mencionar nomes como Lauro Barata, Edson Conde Miranda, Sônia Costa, Ângelo da Cunha Pinto (e outros de quem não lembro no momento), que entraram ainda muito jovens no NPPN e se tornaram figuras de destaque no panorama da educação superior no país. Um bom funcionário da Secretaria pode fazer isso melhor do que eu. Não! O que temos para mostrar é que, ao longo de décadas, todos nós, Paulo Lacaz, Walter Mors, Benjamin Gilbert, Paul Baker, Jaime Rabi, Roderick Barnes, Keith Brown, Bernard Tursch e tantos outros trabalharam juntos como - nem sei como dizer - como irmãos.

Uma lista com tantos nomes se traduz em um número grande de relacionamentos. Pode ser devido à proverbial perda de memória de um homem de 78 anos, mas não consigo me lembrar de uma briga, uma discussão, uma picuinha entre nós. A começar por Lacaz, o tetracatedrático, o fundador, o chefe absoluto, o 'dono' do CPPN; dele só me lembro da ternura de um pai. E se um jovem me perguntasse: “Quem mandava mais no CPPN, Walter ou Gilbert?", eu riria dessa pergunta fora de propósito. Minha mãe me deu quatro irmãs, mas o irmão só vim encontrar quando Lacaz aproveitou que eu estava longe e colocou Walter no meu laboratório.

Devo ter esquecido nomes importantes, fatos relevantes. Peço desculpas aos sobreviventes. Tenho a certeza de que Walter, Gilbert, Jaime, Sônia, Marilu, entre outros, acharão o tempo e a disposição para corrigir minhas falhas. 


\section{Diversidade de origem}

\section{Depoimento de Walter B. Mors}

Neste relato sobre o NPPN quero destacar a diversidade da origem dos membros do grupo. Cada um veio de um canto do mundo. Não houve, portanto, nenhum inbreeding. Affonso Seabra já narrou sua história - carioca, formado pela Faculdade de Farmácia da então Universidade do Brasil, com pós-graduação em Wisconsin, nos Estados Unidos, e Birmingham, na Inglaterra. Mais adiante, revela sua idade -78 anos. Quanto a mim, sou paulista da capital e, com 85 anos, mais velho do que ele. Com base nesses dados, já se pode adivinhar que meu background é totalmente distinto.

Ainda adolescente presenciei a fundação da Universidade de São Paulo (USP), em 1934. Era governador do estado (interventor, diante da assunção de Getúlio Vargas, depois da Revolução de 1932) Armando de Sales Oliveira. Ao criar a nova universidade, ele reuniu as escolas superiores já existentes, faltando para completar o quadro uma Faculdade de Filosofia, Ciências e Letras. Para organizá-la, foi constituída uma comissão que escolheu a dedo os professores a serem contratados na Europa.

Resolvi estudar química e, formado em 1942, pertenci a uma das suas primeiras turmas. Um dia, o professor Rheinboldt, diretor do Instituto de Química, foi contatado por Felisberto Camargo, diretor do recém-criado Instituto Agronômico do Norte (IAN), em Belém do Pará. Ele precisava de um químico e, ao sondaram os alunos da turma do último ano, a próxima a ser formada, imediatamente me apresentei como candidato. Fui o único! Paulista não gosta de sair de São Paulo. Assim fui parar na Amazônia, onde trabalhei no IAN durante quase quatro anos. Em 1947 consegui transferência para o Instituto de Química Agrícola (IQA), no Rio de Janeiro, e lá permaneci cerca de dez anos, até a extinção do órgão, em 1962. No mesmo período elaborei, na Universidade do Brasil, minha tese de livre-docência, que, naquela época, conferia o título de doutor. Realizei, também, estágio com Carl Djerassi na Wayne State University, em Detroit (19551956), com uma bolsa da Fundação Rockefeller. Fui eu que escolhi Djerassi como orientador, em virtude de seus trabalhos sobre produtos naturais, realizados no México. De volta ao Brasil, recebi Benjamin Gilbert no IQA, o primeiro 'embaixador' que Djerassi nos mandou - como muitos sabem, o inglês Ben Gilbert fez do Brasil sua segunda pátria. Outros se juntaram ao nosso grupo, por iniciativa e com o auxílio de Djerassi.

Cito aqui os colegas que gradualmente foram formando o grupo, desde o início, no IQA, até a sua consolidação como CPNN, na Faculdade de Farmácia da UFRJ. Todos nós, químicos e farmacêuticos, tínhamos um ramo de interesse especializado, que nos ligava de alguma forma à biologia. Isso gerava a diversidade de assuntos 
que circunscrevia a entidade, no seu conjunto, na área de pesquisas de produtos naturais, o que se refletia na natureza dos temas das teses orientadas. Eu e Ben Gilbert tínhamos inclinação para a botânica, consolidada por nossa amizade e conseqüente colaboração com os botânicos Carlos Toledo Rizzini e Aparício Pereira Duarte, respectivamente. Affonso Seabra, bioquímico, revelou-se discípulo e sucessor de Lacaz. Os trabalhos de Keith Brown, americano, tinham estreita ligação com a entomologia, especialmente com os corantes de borboletas. A certa altura, Keith passou-se para a Universidade Estadual de Campinas (Unicamp), onde permanece até hoje. Foi acompanhado por Woodruff Benson, também americano e igualmente dedicado à zoologia. Jaime Rabi, chileno, desenvolveu a química de nucleosídios, assunto de sua tese de doutorado na Universidade de Washington. Expandiu esse trabalho para a escala industrial e até hoje produz nucleosídios de atividade farmacológica - antivirais, entre outros. Para completar o quadro, cito Bernard Tursch, de nacionalidade belga. Químico também, tinha grande interesse por biologia marinha, assunto de cujo ramo químico tornou-se um pioneiro no Brasil. Da USP transferiu-se para o NPPN Alfredo Martins de Oliveira, que se dedicou intensamente ao controle dos barbeiros, triatomíneos transmissores da moléstia de Chagas. Sem pertencer propriamente ao quadro de pesquisadores do NPPN, Enio Goulart, professor da Faculdade de Farmácia, estudou o controle ecológico dos transmissores de verminoses.

A extinção do IQA, em 1962, já foi contada por Affonso Seabra e, como consta de seu relato, motivou a criação do CPPN. Ao recordar essa transição, preciso expressar nosso reconhecimento a todos que nos apoiaram naquela hora difícil, tanto os que ajudaram a operar a transferência para a universidade, como os que lá nos receberam, pode-se dizer, de braços abertos. Entre os primeiros destaco a figura de Joaquim Martins Ferreira. Tinha conseguido ingressar no IQA mas não era, para nós, um elemento novo; freqüentava o instituto há muito tempo, como nosso colega e amigo. Como irmão de Hiss Martins Ferreira, do Instituto de Biofísica, Joaquim ficava igualmente à vontade na universidade e tornou-se nosso elemento de ligação com Lacaz. Combinou com este o que tinha a ser feito e providenciou o transporte de material para a Faculdade de Farmácia. Foi ele também que trouxe Marilu para o CPPN.

Outros, na área política e acadêmica, que nos auxiliaram, prestigiaram e deram total apoio foram Antonio Couceiro, presidente do CNPq, e Manoel da Frota Moreira, seu fiel escudeiro, além de José Pelúcio Ferreira, da Finep, e outros que Affonso mencionou em seu depoimento. Foram Couceiro e Frota que, pouco mais tarde, quando já estávamos instalados na Praia Vermelha, alertaram-nos sobre a passagem de Jaime Rabi pelo Brasil, após a conclusão de seu doutorado nos Estados Unidos, e nos ajudaram a mantê-lo aqui. Outro 
que ingressou no NPPN foi Roderick Barnes, depois de ter trabalhado durante uma temporada no IQA, na Universidade Estadual Paulista, em Araraquara, e no Instituto Militar de Engenharia. Barnes já havia feito contato comigo nos Estados Unidos, quando me falou da sua vontade de vir para o Brasil.

Nossa recepção na Faculdade de Farmácia foi cordialíssima. Desde o início percebemos que o ambiente era de entusiasmo e afabilidade; nunca nos sentimos um corpo estranho. É claro que tal receptividade não foi gratuita. Ela demonstrava o grau de reconhecimento que havíamos alcançado na área de pesquisa em produtos naturais. De todo modo, Nuno Alvares Pereira, professor de farmacologia, contou-me que prevalecia nesse grupo um ambiente favorável à pesquisa de produtos naturais, o que talvez explique a decisão instantânea, por parte de Lacaz, de procurar o IQA assim que soube da extinção desse órgão.

Lacaz foi um grande chefe. Exercia sua autoridade com naturalidade, não era prepotente, tratava todos de igual para igual. Devo mencionar também Mário Taveira, diretor da Faculdade de Farmácia, e Jaime Cruz - que pôs à nossa disposição o seu laboratório, assistido por Moacyr Nogueira -, Alcides Jardim, sua esposa Iolanda e Osvaldo Costa, então já aposentado. Entre os que nos receberam com tanta cordialidade e boa vontade, consta ainda Henrique Peres de Souza, há anos secretário da Faculdade de Farmácia, que aplainou para nós os caminhos na instituição em que éramos, afinal, adventícios. Mais tarde, em 1970, já na ilha do Fundão, Lacaz conseguiu levá-lo para o NPPN, como nosso secretário.

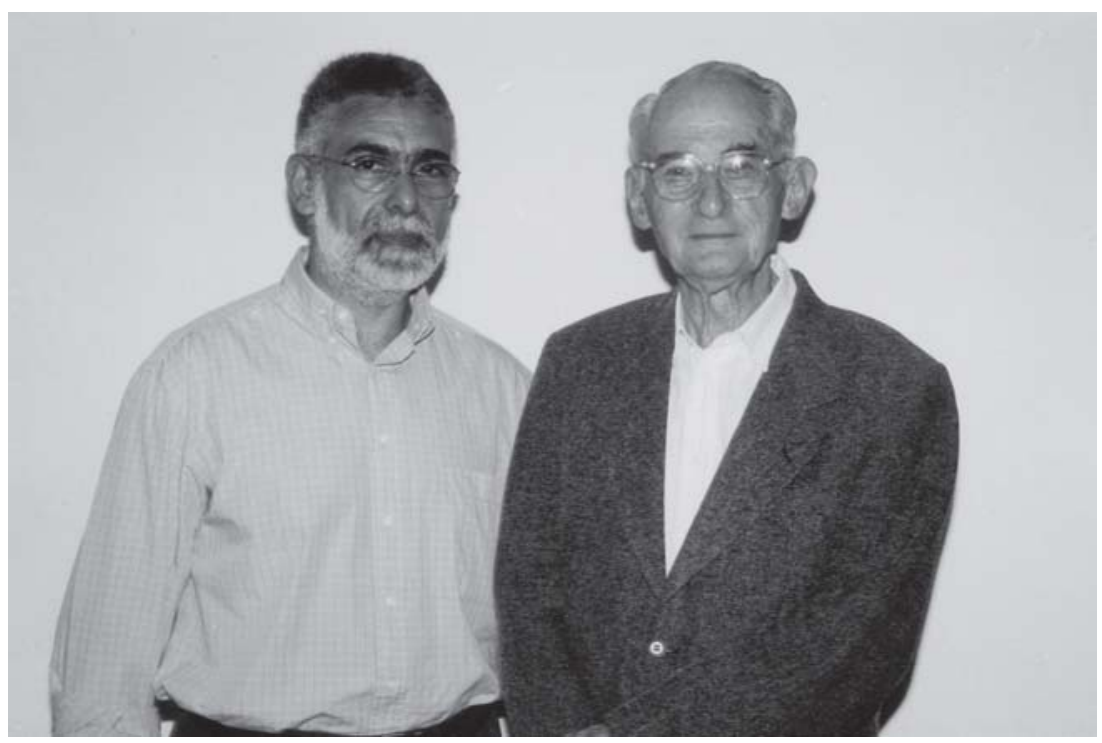

Componentes da equipe de pesquisadores do Núcleo de Pesquisas de Produtos Naturais da UFRJ, professores Jaime Rabi e Walter Mors. (Arquivo pessoal de Walter Mors) 
Na fase da sua formação, o NPPN teve pontos altos. Lembro, emocionado, o dia em que Carlos Chagas Filho, decano do Centro de Ciências da Saúde, chamou a mim e ao Affonso para nos comunicar a aprovação, pelo Conselho Universitário, da mudança de denominação de 'centro' para 'núcleo', legitimando-nos assim no elenco das unidades da Universidade. Ao se despedir, ele disse: "Vocês tiveram agora a sua consagração" - e nos desejou boa sorte. Affonso relatou o enredo (horse trading) que levou a esse importante passo.

De grande impacto também foi a criação da Central Analítica, que durante muito tempo nos manteve na vanguarda da química no Brasil. Outro fato importante foi a construção do auditório do NPPN, na gestão e por iniciativa de Jaime Rabi. A obra foi rematada pelo então decano Doyle-Maia, que tão logo soube da conclusão da obra presenteou-nos com as cadeiras para o anfiteatro. Na ocasião, o decano afirmou que, por serem de qualidade modesta, tais cadeiras seriam provisórias. Trinta anos depois elas lá permanecem, e o 'provisório' perdura até hoje.

Para concluir, deixo uma palavra de incentivo às novas gerações que encontraram tudo isso pronto. Não seria justo que recebessem o que foi construído com tanto trabalho, amor e dedicação, sem dar algo em troca. Como diz a máxima faustiana: "A fim de merecer o legado de teus maiores, conquista-o com teu próprio esforço." (A tradução de Antônio Feliciano de Castilho deve ser melhor do que a minha.) O que devem dar em troca, além da dedicação ao trabalho, cujos resultados elas mesmas irão usufruir, é o que encareci aos jovens, em 1968, ao assumir meu segundo mandato de diretor: "Vistam a camisa do NPPN! Defendam seu nome, façam reverter para a instituição parte dos benefícios e do crédito por vocês auferidos. É o mínimo que podem fazer, e é o que nós, antigos, esperamos que façam para que o NPPN sobreviva".

\section{NOTAS}

${ }^{1}$ Affonso do Prado Seabra nasceu no Rio de Janeiro em 1928. Formado em bioquímica pela Faculdade de Farmácia da então Universidade do Brasil, com pós-graduação na University of Birmingham, na Inglaterra, e na University of Wisconsin, nos Estados Unidos, sob a orientação de Herald Deutsch. Foi convidado por Paulo da Silva Lacaz para integrar a equipe do recém-criado Instituto de Química da Universidade do Brasil. Em 1963, recém-chegado da Inglaterra, foi novamente convidado por Lacaz para incorporar-se ao grupo de cientistas do Centro de Pesquisa de Produtos Naturais.

2 Walter Baptist Mors nasceu em São Paulo, em 1920. Formado em 1942 pela Faculdade de Filosofia, Ciências e Letras da Universidade de São Paulo, é especialista em química de produtos naturais. Em 1943 ingressou no Instituto Agronômico do Norte, órgão do Ministério da Agricultura, dedicando-se a pesquisas sobre o melhoramento do timbó, planta da qual se extrai a rotenona, substância utilizada na fabricação de inseticidas. A entrada no Instituto de Química Agrícola, em 1947, coincidiu com a posse do novo diretor, Taiguara Fleuri de Amorim, que alocou Mors na Seção de Química Vegetal, à época chefiada por Oscar Ribeiro. Entre 1966 e 1973 dirigiu o Centro de Tecnologia Agrícola e Alimentar, órgão que sucedeu o Instituto de Química Agrícola. (Depoimento Walter B. Mors, 22.4.1997 - Casa de Oswaldo Cruz/Fiocruz, citado em Faria, Lina Rodrigues de, Uma ilha de competência: a história do Instituto de Química Agrícola na memória de seus cientistas, História, Ciências, Saúde - Manguinhos, Rio de Janeiro, v.3, n.3, p.51-74, 1997.) 


\section{DEPOIMENTO}

3 Otto R. Gottlieb nasceu em 31 de agosto de 1920 em Brno, Checoslováquia. Transferiu-se para o Brasil em 1939 e graduou-se em química pela Escola Nacional de Química da Universidade do Brasil, em 1945. (Depoimento de Otto Gottlieb, 28.5.1996 e 10.6.1996 - Casa de Oswaldo Cruz/Fiocruz, citado em Faria, Lina Rodrigues de, op. cit.)

${ }^{4}$ Benjamin Gilbert nasceu em 27 de setembro de 1929, na Inglaterra. Em 1954 obteve o Ph.D. em química orgânica pela University of Bristol. Veio para o Brasil em 1958, a convite de Walter Mors e indicado por Carl Djerassi, para ajudar a organizar um laboratório de produtos químicos naturais no Instituto de Química Agrícola. (Depoimento de Benjamin Gilbert, 21.11.1995 e 15.12.1995 - Casa de Oswaldo Cruz/Fiocruz, citado em Faria, Lina Rodrigues de, op. cit.)

${ }^{5}$ Oscar Ribeiro dirigiu a Seção de Química Vegetal do Instituto de Química Agrícola, na época da entrada de Walter Mors na instituição.

${ }^{6}$ Professor catedrático de química orgânica e de bioquímica das Faculdades de Medicina e de Farmácia da Universidade do Brasil. Foi o grande incentivador do Núcleo de Pesquisa de Produtos Naturais, como revelam os presentes depoimentos de Seabra e Mors.

${ }^{7}$ A história do IQA até a sua extinção está descrita em artigo de Lina Rodrigues de Faria, op. cit.

8 Entre os anos de 1963 e 1971 o Instituto de Química Agrícola, já desestruturado, passou por sucessivas mudanças de denominação e atribuições. Chamou-se Divisão de Tecnologia Agrícola e Alimentar; em seguida, Divisão de Tecnologia Alimentar; em 1969 reassumiu o primeiro nome e dois anos depois foi incorporado ao Centro de Tecnologia Agrícola e Alimentar da Empresa Brasileira de Pesquisa Agropecuária.

${ }^{9}$ Depoimento de Walter B. Mors, 21.1.1997 e 22.4.1997 - Casa de Oswaldo Cruz/Fiocruz, citado em Faria, Lina Rodrigues de, op. cit.

10 Entre os anos de 1963 e 1972 o Centro de Pesquisas de Produtos Naturais ocupou parte das dependências da Faculdade de Farmácia, no campus da Praia Vermelha. Posteriormente instalou-se no bloco H do prédio do Centro de Ciências da Saúde da UFRJ, na ilha do Fundão. Paulo Lacaz recebeu três andares, dos quais dois foram cedidos para a implantação do centro.

${ }^{11}$ Hoje o núcleo conta com vários laboratórios, entre eles o de Biologia e um de Síntese e Transformação de Produtos Naturais, com equipamentos de ponta e um quadro de pesquisadores de sólida formação, todos com doutorado e dedicação exclusiva, além de docentes colaboradores, entre os quais se inclui o próprio Walter Mors, já aposentado.

${ }^{12}$ Formada em farmácia e bioquímica pela Universidade Federal de Minas Gerais, é professora adjunta da UFRJ e diretora do NPPN.

Recebido para publicação em fevereiro de 2006.

Aprovado para publicação em setembro de 2006. 